Article

\title{
Qualitative and Quantitative Analysis of Andrographis paniculata by Rapid Resolution Liquid Chromatography/Time-of-Flight Mass Spectrometry
}

\author{
Yong-Xi Song ${ }^{1, \dagger}, *$, Shi-Ping Liu ${ }^{1, \dagger}$, Zhao Jin ${ }^{1}$, Jian-Fei Qin ${ }^{2, *}$ and Zhi-Yuan Jiang ${ }^{3}$
}

1 Department of Pharmacy, The First Affiliated Hospital of Harbin Medical University, Harbin 150001, China; E-Mails: shipingliu@sina.com (S.-P.L.); shipingliu666@126.com (Z.J.)

2 Harbin Sanlian Pharmaceutical Co., LTD, Harbin 150025, China

3 Heilongjiang Province Agricultural Reclamation Administration of the Centers for Disease Control and Prevention, Harbin 150090, China; E-Mail: zhongyao150001@126.com

$\dagger$ These authors contributed equally to this work.

* Authors to whom correspondence should be addressed; E-Mails: yongxisong@163.com (Y.-X.S.); jianfeiqin@126.com (J.-F.Q.); Tel.: +86-451-8555-5689 (Y.-X.S.); Fax: +86-451-5364-2755 (Y.-X.S.); $+86-451-5735-5698$ (J.-F.Q.).

Received: 29 August 2013; in revised form: 18 September 2013 / Accepted: 26 September 2013 / Published: 30 September 2013

\begin{abstract}
A rapid resolution liquid chromatography/time-of-flight tandem mass spectrometry (RRLC-TOF/MS) method was developed for qualitative and quantitative analysis of the major chemical constituents in Andrographis paniculata. Fifteen compounds, including flavonoids and diterpenoid lactones, were unambiguously or tentatively identified in $10 \mathrm{~min}$ by comparing their retention times and accurate masses with standards or literature data. The characteristic fragmentation patterns of flavonoids and diterpenoid lactones were summarized, and the structures of the unknown compounds were predicted. Andrographolide, dehydroandrographolide and neoandrographolide were further quantified as marker substances. It was found that the calibration curves for all analytes showed good linearity $\left(R^{2}>0.9995\right)$ within the test ranges. The overall limits of detection (LODs) and limits of quantification (LOQs) were $0.02 \mu \mathrm{g} / \mathrm{mL}$ to $0.06 \mu \mathrm{g} / \mathrm{mL}$ and $0.06 \mu \mathrm{g} / \mathrm{mL}$ to $0.2 \mu \mathrm{g} / \mathrm{mL}$, respectively. The relative standard deviations (RSDs) for intra- and inter-day precisions were below $3.3 \%$ and $4.2 \%$, respectively. The mean recovery rates ranged from $96.7 \%$ to $104.5 \%$ with the relative standard deviations (RSDs) less than $2.72 \%$. It is concluded that RRLC-TOF/MS is powerful and practical in
\end{abstract}


qualitative and quantitative analysis of complex plant samples due to time savings, sensitivity, precision, accuracy and lowering solvent consumption.

Keywords: Andrographis paniculata; rapid resolution liquid chromatography; time-of-flight tandem mass; diterpenoid lactones

\section{Introduction}

Andrographis paniculata (Burm.f.) Nees (Acanthaceae) known as Chuan-xin-lian in Chinese, is widely used in China, India, and other Southeast Asian countries [1]. A. paniculata has also been recorded in the Chinese Pharmacopoeia for a long time [2]. It possesses various pharmacological effects for the treatment of the common cold, fever and non-infectious diarrhea $[3,4]$. Many Chinese medical preparations containing A. paniculata or its extract are listed in Chinese Pharmacopoeia, such as "Chuanxinlian tablet", "Andrographolide drop pill", "Chuanxinlian capsule", et al. [2]. The main active constituents of $A$. paniculata include flavonoids and diterpenes, especially labdane diterpenes such as andrographolide, dehydroandrographolide and neoandrographolide [5-9]. A number of pharmacological activities of these marker components were previously reported [10-16].

Several chromatographic methods have been reported for analysis of these diterpenoids, including thin-layer chromatography, high performance liquid chromatography, and capillary electrophoresis. However, most of them could only determine two or three constituents [17-24]. Moreover, these methods seemed to be associated with some disadvantages such as complicated sample preparation, low sensitivity and time-consuming. Most recently, a quantitative proton nuclear magnetic resonance technique has been successfully applied to quantify andrographolide, dehydroandrographolide, deoxyandrographolide and neoandrographolide in A. paniculata [25]. However, nuclear magnetic resonance instruments are still inaccessible for most laboratories worldwide.

In this study, a rapid resolution liquid chromatography/time-of-flight tandem mass spectrometry (RRLC-TOF) was developed to identify and quantify the major constituents of $A$. paniculata. From the point of view of reducing the consumption of solvent and time savings, RRLC-TOF/MS may be a quite useful technique to identify and determine active constituents in Traditional Chinese Medicines, becoming a valuable addition to the existing analysis tools.

\section{Results and Discussion}

\subsection{Optimization of Sample Preparation and Chromatographic Conditions}

Andrographolide (6), dehydroandrographolide (8) and neoandrographolide (11) are selected as marker compounds for investigating the extract yields by a common HPLC-UV method. Their chemical structures can be seen in Figure 1. The extraction solvent plays a critical role in obtaining a satisfactory extraction of compounds from plant samples and in obtaining a good chromatographic fingerprint representing the quality control of a herbal medicine. In this study, ethanol, methanol and acetonitrile were used as extraction solvents. As shown in Figure 2A, except for compound 8, ethanol 
exhibits relatively higher extraction efficiency for compounds $\mathbf{6}$ and $\mathbf{1 1}$ as compared to methanol and acetonitrile. Thus, considering safety and economy, ethanol was applied for the subsequent experiments.

Figure 1. The structures of compounds identified in Andrographis paniculata.

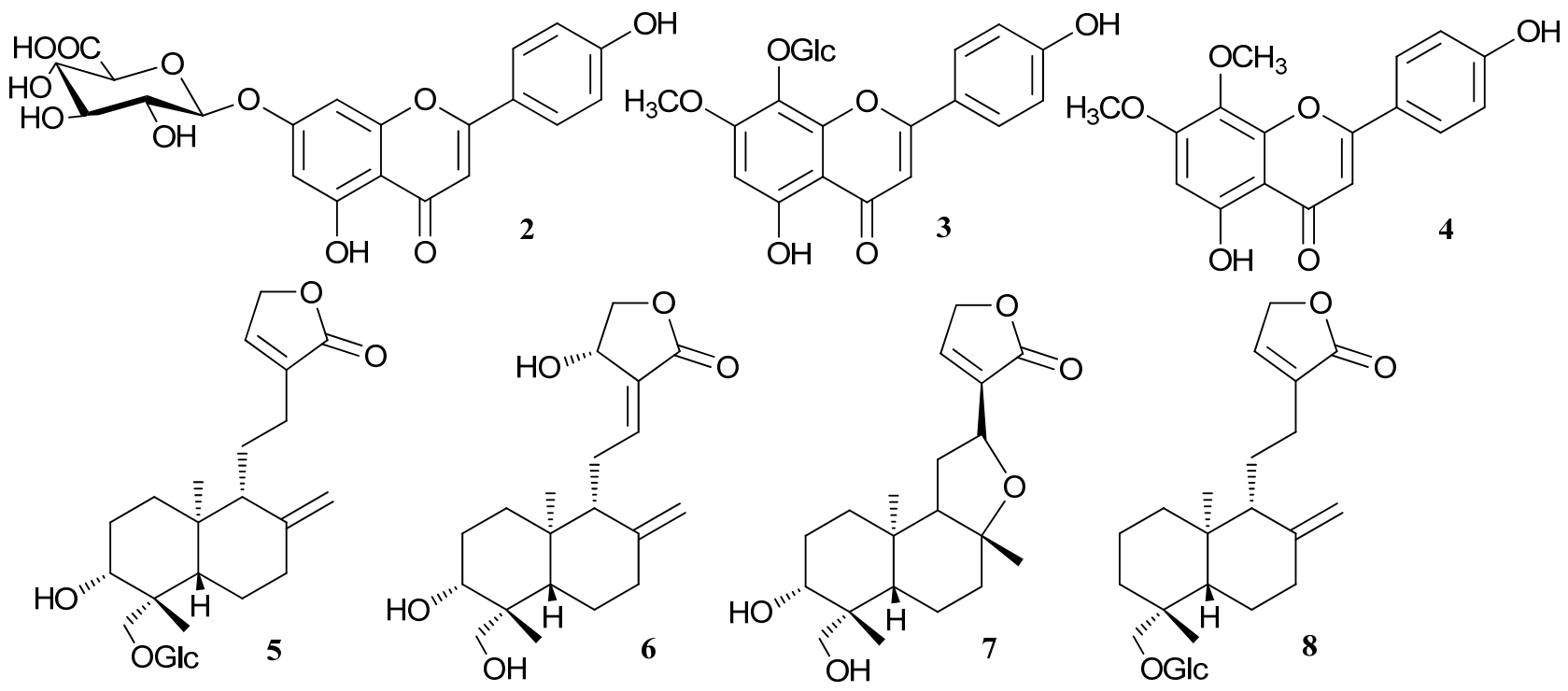<smiles>C=C1CC[C@H]2[C@@](C)(CC[C@@H](O)[C@@]2(C)CO)[C@@H]1CCC1=CCOC1=O</smiles>

Extraction time had a close relationship with extraction efficiency. In the assay, extraction efficiency in samples $(0.2 \mathrm{~g})$ was compared by sonication with $10 \mathrm{~mL}$ of ethanol at $60 \mathrm{kHz}$ for 5,15 , 30 and $40 \mathrm{~min}$, respectively. The results indicated that the highest extraction efficiency was obtained by sonication for $30 \mathrm{~min}$ in pure ethanol (Figure 2B). In this study, effects of the ethanol concentration $(30 \% ; 50 \% ; 70 \% ; 100 \%)$ and volume $(5 ; 10 ; 25 ; 40 \mathrm{~mL})$ on the extracting yield were also investigated. By comparing peak areas of the three markers, it was found that, when $70 \%$ ethanol was employed, the peak areas of the three investigated components reached the highest values (Figure 2C). Generally, usage of larger volume of extracting solvent could obtain larger amount of extract [26]. Sometimes, the large ratio of liquid to material also resulted in the decrease of extraction yield [27]. In this study, the significant decrease of yield of $\mathbf{8}$ was observed when $40 \mathrm{~mL}$ of $70 \%$ ethanol was used. However, when $25 \mathrm{~mL}$ of $70 \%$ ethanol was applied, the yield of $\mathbf{6}$ and 11 was obviously decreasing. Thus, $10 \mathrm{~mL}$ of $70 \%$ ethanol may be a better choice to compromise (Figure 2D). Finally, effects of sonication frequency $(40,50,60$ and $70 \mathrm{kHz})$ on the extracting yield were investigated. The results indicated that the highest extraction efficiency was obtained by sonication at $50 \mathrm{kHz}$ (Figure 2E). 
Figure 2. Effects of the types of extraction solvent (A), time (B), concentration of solvents (C), ratio of liquid to solid (D) and ultrasonic frequency $(\mathbf{E})$ were investigated on yields of andrographolide (6), neoandrographolide (8) and dehydroandrographolide (11) in A. paniculata.

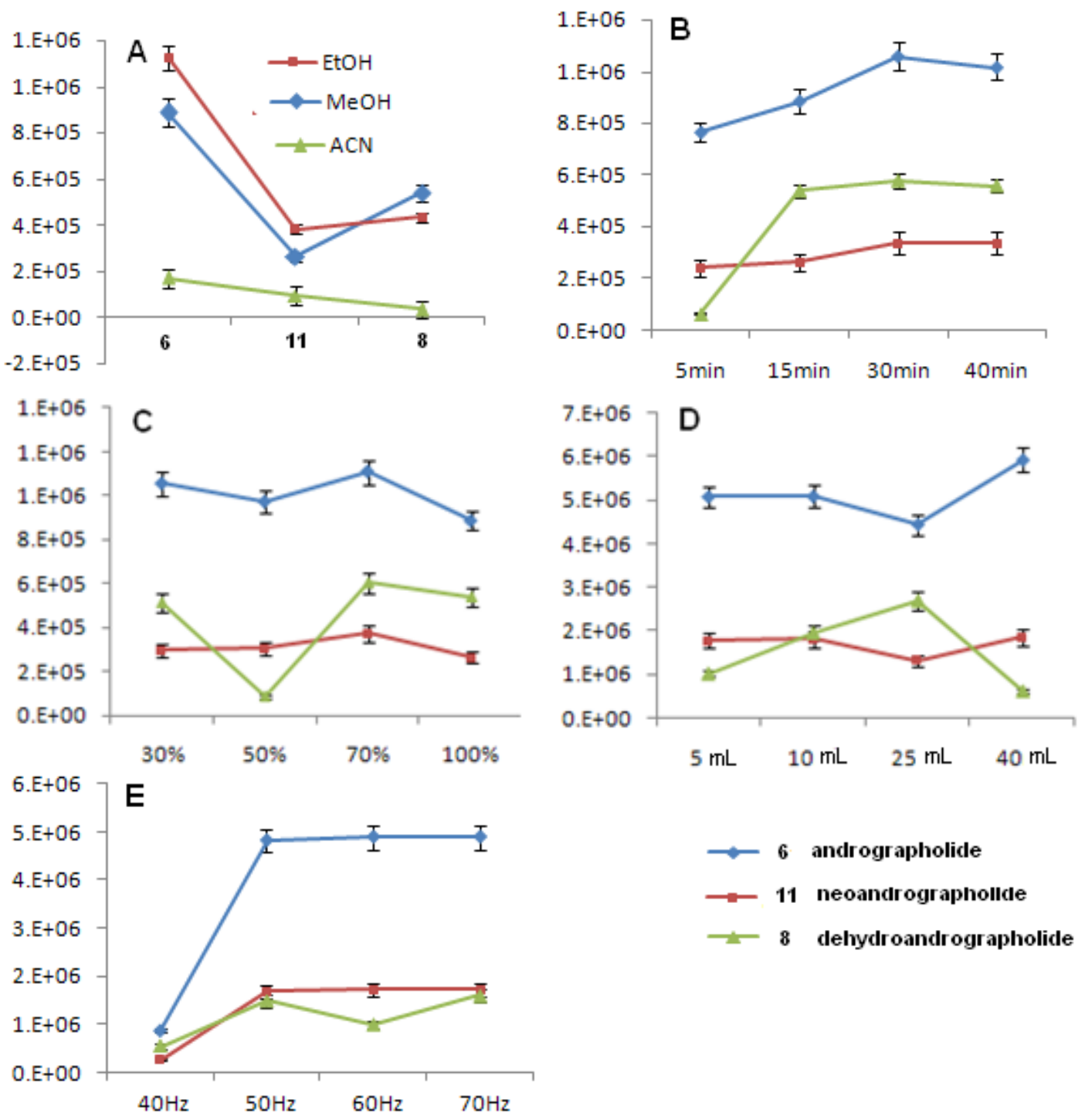

From the above experiments, it was demonstrated that the most suitable ultrasonic extraction condition for the three markers from Andrographis paniculata was $0.2 \mathrm{~g}$ plant sample with $10 \mathrm{~mL}$ of $70 \%$ ethanol and extraction for $30 \mathrm{~min}$ at under $50 \mathrm{kHz}$ ultrasonic irradiation.

By testing different types of chromatographic columns it was determined that an ACE C18 column is suitable for separating the bioactive constituents in $A$. paniculata. The selection of mobile phase played an important role in achieving good chromatographic separation and appropriate ionization. The effect of different mobile phase compositions on chromatographic separation was compared. Acetonitrile-water possessed higher resolution and better peak shape than methanol-water. Several mobile phase additives, such as formic acid, acetic acid and ammonium acetate, were used to achieve better resolution of the analytes. It was found that the good signal intensity, resolution and peak shape were achieved when formic acid was added to both acetonitrile and aqueous solution. But with the adding amount of formic acid increasing, the signal intensity had the downward trend. Ultimately, $0.1 \%$ formic acid added to the mobile phase was suitable. There was no sharp effect upon changing the 
column temperature $\left(25-35^{\circ} \mathrm{C}\right)$ on either the peak symmetry or the resolution of the eluted peaks, but only a marked increasing in the retention time and so the column temperature of $35{ }^{\circ} \mathrm{C}$ was used. The effect of different flow rates $(0.2-0.4 \mathrm{~mL} / \mathrm{min})$ has been also examined. There was no obvious tailing and poor peaks symmetry appeared at lower values of the flow rate, so $0.2 \mathrm{~mL} / \mathrm{min}$ was selected as the optimum flow rate. Under these optimum conditions, all the studied chemical constituents were well separated from each other by RRLC-TOF/MS method (Figure 3A).

Figure 3. (A) Total ion chromatogram in positive ion mode of A. paniculata; (B) The narrow widow extracted ion chromatograms (nwXICs) chromatograms for $\mathrm{m} / z 297.187$ (6 and 11); (C) The nwXICs chromatograms for $\mathrm{m} / z$ 319.224 (8). The retention time is defined as the minute.

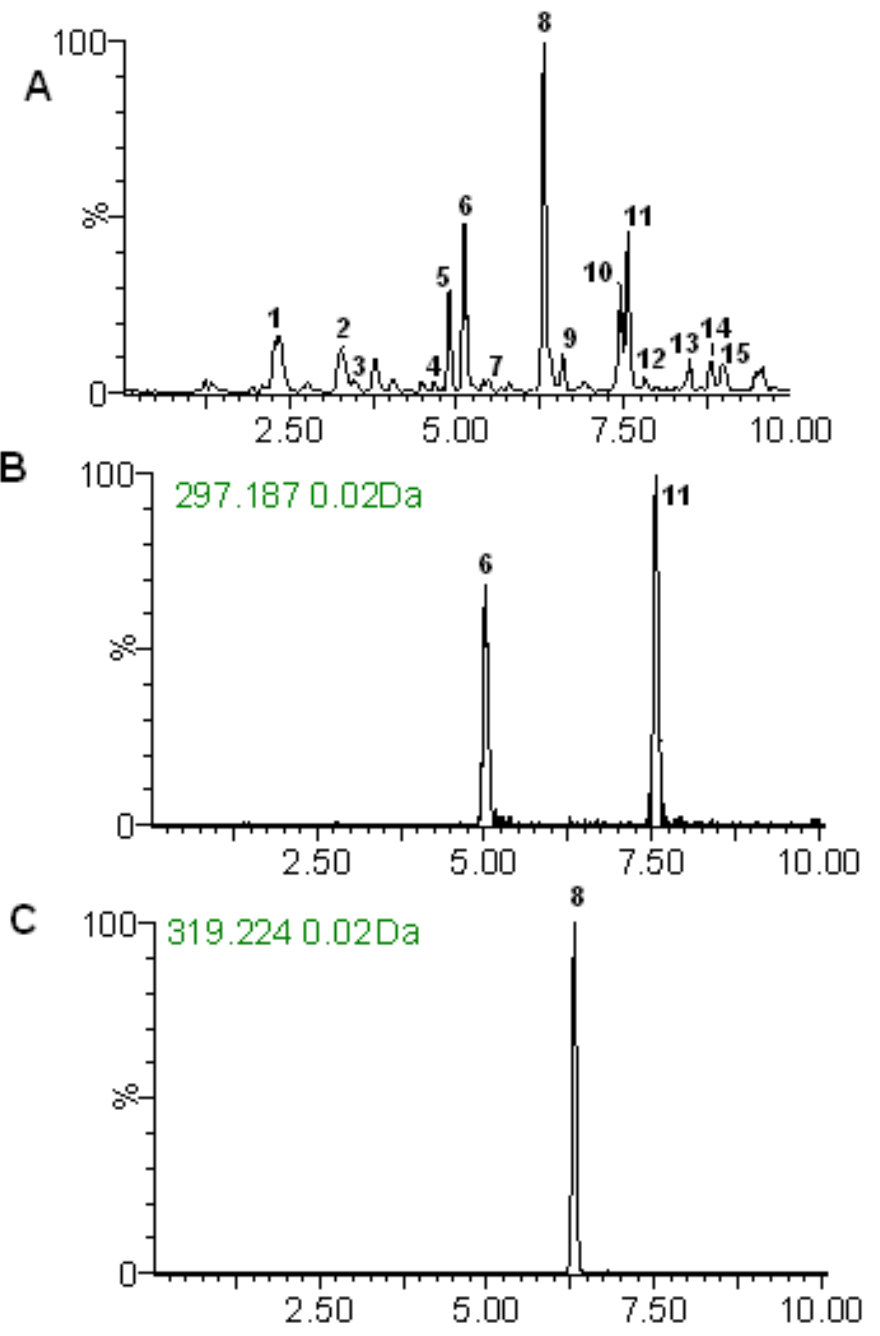

\subsection{RRLC-TOF Analysis}

\subsubsection{Identification of Diterpene Lactones}

Ten diterpene lactones were detected in A. paniculata and their structures are shown in Figure 1. These compounds were classified into monomers and polymers of diterpene lactones. The positive ion mode was much more useful for the analysis of these kinds of compounds. Compounds 5-11 and $\mathbf{1 3}$ 
are monomers with multiple hydroxyls group in their structures whose characteristic fragmentation behavior was the successive loss of one, two and multiple $\mathrm{H}_{2} \mathrm{O}$ molecules [28,29]. Compounds 5 and 8 have glucosyl groups attached to the core molecules by glycosidic linkages which were readily dissociated, so their characteristic fragment ions were formed by the losses of a glucosyl group (162 Da). Figure 4 is mass spectrum of compound $\mathbf{6}$, which is a typical monomer. A plausible fragmentation pathway of $\mathbf{6}$ is shown in Scheme 1.

Figure 4. ESI (+) MS spectrum of compound 6.

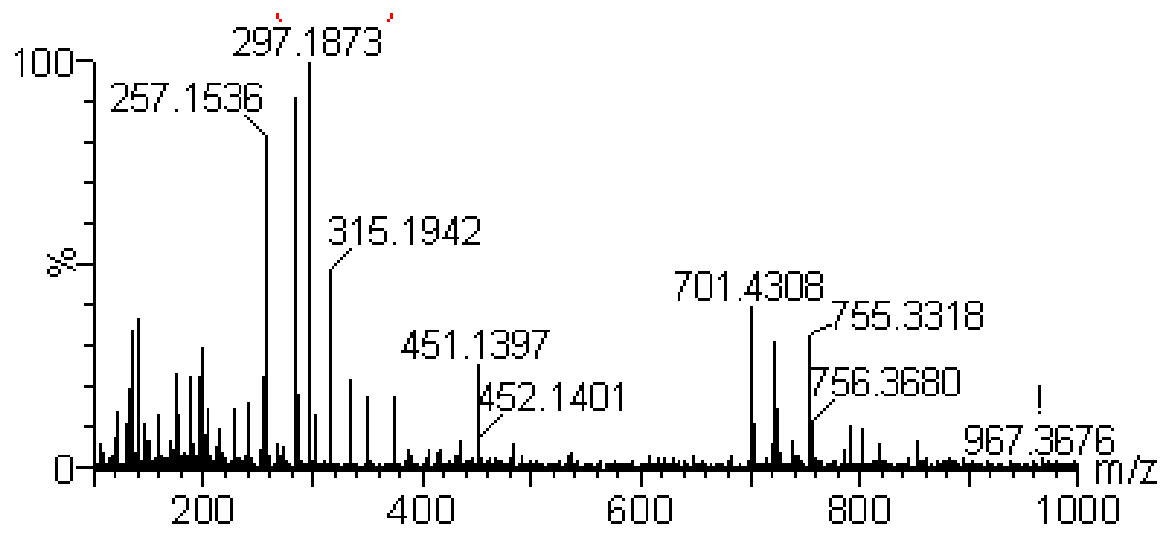

Scheme 1. The proposed fragmentations pathways of andrographolide (6).<smiles>C=C1CCC2[C@@H](CC[C@@H](O)[C@]2(C)O)[C@@H]1C/C=C1/C(=O)OC[C@H]1O</smiles>

$m / z 351.2164$<smiles>C=C1CC[C@H]2[C@@H](CC/C=C3\C=COC3=O)[C@H](CO)[C@@]2(CO)[C@@H]1O</smiles>

$m / z 333.2063$<smiles></smiles>

$m / z 315.1942$

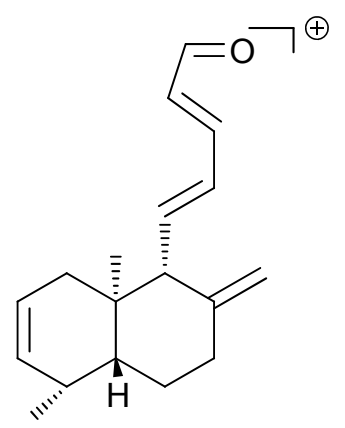

$m / z 257.1536$ $m / z 285.1804$

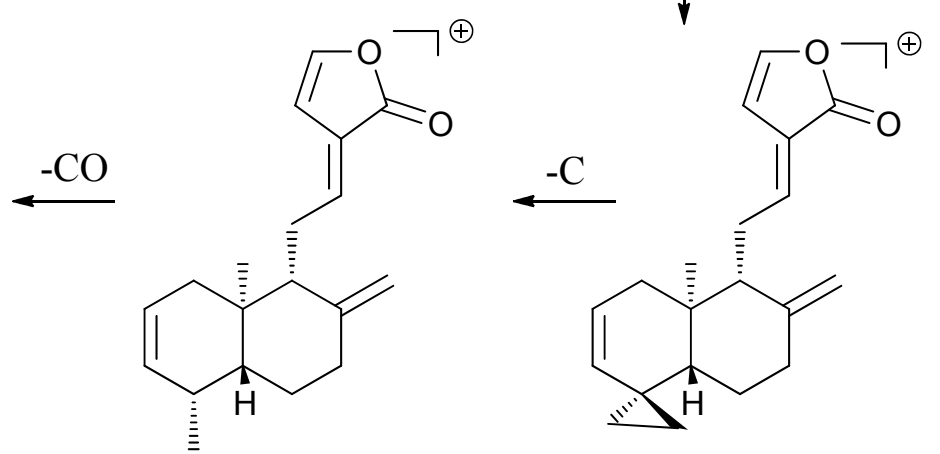

$m / z 297.1873$

On the basis of above analysis, compounds 6, 8 and 11 were unambiguously identified as andrographolide, neoandrographolide and dehydroandrographolide by comparison with authentic 
references under the same chromatography conditions. Compounds 5, 7, 10 and 13 were tentatively identified as 14-deoxyandrographiside, isoandrographolide, 14-deoxyandrographolide and 3,19-dihydroxy-15-methoxy-ent-labda-8(17),11,13-trien-16,15-olide, respectively, by exact molecular formulae matching, fragmentation information and retention behaviors as well as the literature data $[6,8,9]$. However, compound 9 was an unreported natural product, tentatively identified as hydroxylated compound $\mathbf{1 3}$ by comparison of the exact molecular formulae with compound $\mathbf{1 3}$ and their fragmentation information [9]. However, it is difficult to determine the position of hydroxylation by the single mass method. Both 12 and 15, bis-andrographolide compounds, are unreported natural products, which are different from the reported bis-andrographolides A-D in A. paniculata [30,31]. Taking compound 12 as example, it showed a molecular ion at $\mathrm{m} / z[\mathrm{M}+\mathrm{H}]^{+} 681.3962$ and with successive loss of four molecules of water followed by a fragment ion at $\mathrm{m} / \mathrm{z} 663.3945,645.3752$, 627.3672 and 609.3548. The further fragment ion at $\mathrm{m} / \mathrm{z} 297.1833$ supports the proposed the hypothesis that compound $\mathbf{1 2}$ should be a bis-andrographolide compound.

\subsubsection{Identification of Flavone Compounds}

The characteristic fragmentation behavior of the flavone aglycones (compounds 4 and 14) were loss of $\mathrm{CO}(28 \mathrm{Da})$ and a reverse Diels-Alder $(\mathrm{RDA})$ reaction $[32,33]$. The peak of $\left[\mathrm{M}+\mathrm{H}-2 \mathrm{CH}_{3}\right]^{+}$at suggested two $\mathrm{OCH}_{3}$ substitutions on compounds 4 and 14. In the MS/MS spectra of compound 4, the fragment ions with the highest abundance at $\mathrm{m} / \mathrm{z}$ 287.0906, 197.0449 and 153.0541 (Table 1), suggesting the 5-hydroxy-7,8-dimethoxy-substitution may be located in the flavone A ring, so compound 4 was tentatively identified as 5,4'-dihydroxy-7,8-dimethoxyflavone by the exact molecular formulae matching and fragmentation information retention behaviors. The possible fragmentation pathway of compound $\mathbf{4}$ is summarized in Scheme 2. Meanwhile, compound 14 showed similar fragmentation and had the same molecule weight with compound $\mathbf{4}$, so it was tentatively identified as an isomer of compound $\mathbf{1 4 .}$

Scheme 2. The proposed fragmentations pathways of compound 4.




Table 1. Quasi-molecular ions of compounds in A. paniculata sample by RRLC-TOF analysis.

\begin{tabular}{|c|c|c|c|c|}
\hline No. & $t_{R}(\min )$ & MS and MS/MS $(\mathrm{m} / \mathrm{z})$ & Type & Identification \\
\hline 1 & 2.33 & $\begin{array}{l}{[\mathrm{M}+\mathrm{H}]^{+} 463.3319} \\
{\left[\mathrm{M}+\mathrm{H}-\mathrm{H}_{2} \mathrm{O}\right]^{+} 445.3206} \\
{[\text { Aglycone }+\mathrm{H}]^{+} 287.0592}\end{array}$ & Flavone & Unknown \\
\hline 2 & 3.28 & $\begin{array}{l}{[\mathrm{M}+\mathrm{H}]^{+} 447.0887} \\
\text { Calculated }[\mathrm{M}+\mathrm{H}]^{+} 447.0927 \\
{[2 \mathrm{M}+\mathrm{H}]^{+} 893.1624} \\
{[\text { Aglycone }+\mathrm{H}]^{+} 271.0568}\end{array}$ & Flavone & Apigenin-7-O- $\beta$-D-glucuronide \\
\hline 3 & 3.49 & $\begin{array}{l}{[\mathrm{M}+\mathrm{H}]^{+} 463.1211} \\
\text { Calculated }[\mathrm{M}+\mathrm{H}]^{+} 463.1240 \\
{\left[\mathrm{M}+\mathrm{H}-\mathrm{H}_{2} \mathrm{O}\right]^{+} 445.3185} \\
{[\text { Aglycone }+\mathrm{H}]^{+} 301.0673}\end{array}$ & Flavone & $\begin{array}{l}\text { (5,4'-dihydroxy-7-methoxy-8-O- } \beta \text { - } \\
\text { D-glucopyrarosyl-flavone }\end{array}$ \\
\hline 4 & 4.67 & $\begin{array}{l}{[\mathrm{M}+\mathrm{H}]^{+} 315.0859} \\
\text { Calculated }[\mathrm{M}+\mathrm{H}]^{+} 315.0869 \\
{[\mathrm{M}+\mathrm{H}-\mathrm{CO}]^{+} 287.1990} \\
{\left[\mathrm{M}+\mathrm{H}-2 \mathrm{CH}_{3}\right]^{+} 285.1879} \\
{\left[\mathrm{M}+\mathrm{H}-\mathrm{CH}_{3}\right]^{+} 300.0630} \\
\text { Typical fragment } 287.2906 \\
\text { Typical fragment } 197.0449 \\
\text { Typical fragment } 153.0941\end{array}$ & Flavone & $\begin{array}{l}\text { 5,4'-dihydroxy-7,8-dimethoxy- } \\
\text { flavone }\end{array}$ \\
\hline 5 & 4.89 & $\begin{array}{l}{[\mathrm{M}+\mathrm{H}]^{+} 497.2740} \\
\text { Calculated }[\mathrm{M}+\mathrm{H}]^{+} 497.2751 \\
{[\mathrm{M}+\mathrm{H}-\mathrm{Glc}]^{+} 335.2223} \\
{\left[\mathrm{M}+\mathrm{H}-\mathrm{Glc}-\mathrm{H}_{2} \mathrm{O}\right]^{+} 317.2087} \\
{\left[\mathrm{M}+\mathrm{H}-\mathrm{Glc}-2 \mathrm{H}_{2} \mathrm{O}\right]^{+} 299.1959} \\
\text { Typical fragment } 287.1954 \\
\text { Typical fragment } 259.1660 \\
{[\mathrm{M}+\mathrm{Na}]^{+} 519.2543} \\
{[2 \mathrm{M}+\mathrm{H}]^{+} 993.5358}\end{array}$ & Diterpene & 14-deoxyandrographiside \\
\hline 6 & 5.11 & $\begin{array}{l}{[\mathrm{M}+\mathrm{H}]^{+} 351.2164} \\
\text { Calculated }[\mathrm{M}+\mathrm{H}]^{+} 351.2171 \\
{\left[\mathrm{M}+\mathrm{H}-\mathrm{H}_{2} \mathrm{O}\right]^{+} 333.2063} \\
{\left[\mathrm{M}+\mathrm{H}-2 \mathrm{H}_{2} \mathrm{O}\right]^{+} 315.1929} \\
{\left[\mathrm{M}+\mathrm{H}-3 \mathrm{H}_{2} \mathrm{O}\right]^{+} 297.1798} \\
\text { Typical fragment } 285.1804 \\
\text { Typical fragment } 257.1501 \\
{[2 \mathrm{M}+\mathrm{H}]^{+} 701.4224}\end{array}$ & Diterpene & Andrographolide \\
\hline 7 & 5.40 & $\begin{array}{l}{[\mathrm{M}+\mathrm{H}]^{+} 351.2173} \\
\text { Calculated }[\mathrm{M}+\mathrm{H}]^{+} 351.2171 \\
{\left[\mathrm{M}+\mathrm{H}-\mathrm{H}_{2} \mathrm{O}\right]^{+} 333.2065} \\
{\left[\mathrm{M}+\mathrm{H}-2 \mathrm{H}_{2} \mathrm{O}\right]^{+} 315.1954} \\
{\left[\mathrm{M}+\mathrm{H}-3 \mathrm{H}_{2} \mathrm{O}\right]^{+} 297.1828} \\
\text { Typical fragment } 285.1847 \\
\text { Typical fragment } 257.1558 \\
{[2 \mathrm{M}+\mathrm{H}]^{+} 701.4210}\end{array}$ & Diterpene & Isoandrographolide \\
\hline
\end{tabular}


Table 1. Cont.

\begin{tabular}{|c|c|c|c|c|}
\hline No. & $t_{R}(\min )$ & MS and MS/MS $(m / z)$ & Type & Identification \\
\hline \multirow{9}{*}{8} & \multirow{9}{*}{6.30} & {$[\mathrm{M}+\mathrm{H}]^{+} 481.2825$} & \multirow[t]{9}{*}{ Diterpene } & \multirow[t]{9}{*}{ Neoandrographolide } \\
\hline & & Calculated $[\mathrm{M}+\mathrm{H}]^{+} 481.2801$ & & \\
\hline & & {$[\mathrm{M}+\mathrm{H}-\mathrm{Glc}]^{+} 319.2288$} & & \\
\hline & & {$\left[\mathrm{M}+\mathrm{H}-\mathrm{Glc}-\mathrm{H}_{2} \mathrm{O}\right]^{+} 301.2125$} & & \\
\hline & & Typical fragment 289.2166 & & \\
\hline & & Typical fragment 261.1866 & & \\
\hline & & {$[\mathrm{M}+\mathrm{Na}]^{+} 503.2672$} & & \\
\hline & & {$\left[\mathrm{M}+\mathrm{NH}_{4}\right]^{+} 498.3100$} & & \\
\hline & & {$[2 \mathrm{M}+\mathrm{H}]^{+} 961.5472$} & & \\
\hline \multirow{10}{*}{9} & \multirow{10}{*}{6.60} & {$[\mathrm{M}+\mathrm{H}]^{+} 379.2119$} & \multirow[t]{10}{*}{ Diterpene } & \multirow[t]{10}{*}{ Unknown } \\
\hline & & {$[\mathrm{M}+\mathrm{Na}]^{+} 401.1998$} & & \\
\hline & & {$[\mathrm{M}+\mathrm{K}]^{+} 417.1768$} & & \\
\hline & & {$\left[\mathrm{M}+\mathrm{H}-\mathrm{H}_{2} \mathrm{O}\right]^{+} 361.2029$} & & \\
\hline & & {$\left[\mathrm{M}+\mathrm{H}-2 \mathrm{H}_{2} \mathrm{O}\right]^{+} 343.1904$} & & \\
\hline & & {$\left[\mathrm{M}+\mathrm{H}-2 \mathrm{H}_{2} \mathrm{O}-\mathrm{CH}_{2}\right]^{+} 329.1776$} & & \\
\hline & & {$\left[\mathrm{M}+\mathrm{H}-3 \mathrm{H}_{2} \mathrm{O}-\mathrm{CH}_{2}\right]^{+} 311.1636$} & & \\
\hline & & Typical fragment 283.1701 & & \\
\hline & & Typical fragment 257.1414 & & \\
\hline & & {$[2 \mathrm{M}+\mathrm{H}]^{+} 757.4134$} & & \\
\hline \multirow{8}{*}{10} & \multirow{8}{*}{7.44} & {$[\mathrm{M}+\mathrm{H}]^{+} 335.2202$} & \multirow[t]{8}{*}{ Diterpene } & \multirow[t]{8}{*}{ 14-deoxyandrographolide } \\
\hline & & Calculated $[\mathrm{M}+\mathrm{H}]^{+} 335.2222$ & & \\
\hline & & {$[\mathrm{M}+\mathrm{Na}]^{+} 357.2104$} & & \\
\hline & & {$\left[\mathrm{M}+\mathrm{H}-\mathrm{H}_{2} \mathrm{O}\right]^{+} 317.2092$} & & \\
\hline & & {$\left[\mathrm{M}+\mathrm{H}-2 \mathrm{H}_{2} \mathrm{O}\right]^{+} 299.1965$} & & \\
\hline & & Typical fragment 287.1896 & & \\
\hline & & Typical fragment 259.1652 & & \\
\hline & & {$[2 \mathrm{M}+\mathrm{H}]^{+} 669.4372$} & & \\
\hline \multirow{7}{*}{11} & \multirow{7}{*}{7.57} & {$[\mathrm{M}+\mathrm{H}]^{+} 333.2075$} & \multirow[t]{7}{*}{ Diterpene } & \multirow[t]{7}{*}{ Dehydroandrographolide } \\
\hline & & Calculated $[\mathrm{M}+\mathrm{H}]^{+} 333.2066$ & & \\
\hline & & {$\left[\mathrm{M}+\mathrm{H}-\mathrm{H}_{2} \mathrm{O}\right]^{+} 315.1942$} & & \\
\hline & & {$\left[\mathrm{M}+\mathrm{H}-2 \mathrm{H}_{2} \mathrm{O}\right]^{+} 297.1787$} & & \\
\hline & & Typical fragment 285.1805 & & \\
\hline & & Typical fragment 257.1506 & & \\
\hline & & {$[2 \mathrm{M}+\mathrm{H}]^{+} 665.4048$} & & \\
\hline \multirow{8}{*}{12} & \multirow{8}{*}{7.83} & {$[\mathrm{M}+\mathrm{H}]^{+} 681.3962$} & \multirow[t]{8}{*}{ Diterpene } & \multirow[t]{8}{*}{ Unknown $\bigodot$} \\
\hline & & {$[\mathrm{M}+\mathrm{Na}]^{+} 703.3758$} & & \\
\hline & & {$\left[\mathrm{M}+\mathrm{H}-\mathrm{H}_{2} \mathrm{O}\right]^{+} 663.3945$} & & \\
\hline & & {$\left[\mathrm{M}+\mathrm{H}-2 \mathrm{H}_{2} \mathrm{O}\right]^{+} 645.3752$} & & \\
\hline & & {$\left[\mathrm{M}+\mathrm{H}-3 \mathrm{H}_{2} \mathrm{O}\right]^{+} 627.3672$} & & \\
\hline & & {$\left[\mathrm{M}+\mathrm{H}-4 \mathrm{H}_{2} \mathrm{O}\right]^{+} 609.3548$} & & \\
\hline & & Typical fragment 297.1833 & & \\
\hline & & Typical fragment 269.1812 & & \\
\hline
\end{tabular}


Table 1. Cont.

\begin{tabular}{|c|c|c|c|c|}
\hline No. & $t_{R}(\min )$ & MS and MS/MS $(m / z)$ & Type & Identification \\
\hline 13 & 8.48 & $\begin{array}{l}{[\mathrm{M}+\mathrm{H}]^{+} 363.2169} \\
\text { Calculated }[\mathrm{M}+\mathrm{H}]^{+} 363.2171 \\
{[\mathrm{M}+\mathrm{Na}]^{+} 385.1991} \\
{\left[\mathrm{M}+\mathrm{H}-\mathrm{H}_{2} \mathrm{O}\right]^{+} 345.2104} \\
{\left[\mathrm{M}+\mathrm{H}-2 \mathrm{H}_{2} \mathrm{O}\right]^{+} 327.1988} \\
{\left[\mathrm{M}+\mathrm{H}-2 \mathrm{H}_{2} \mathrm{O}-\mathrm{CH}_{2}\right]^{+} 313.1779} \\
{\left[\mathrm{M}+\mathrm{H}-3 \mathrm{H}_{2} \mathrm{O}-\mathrm{CH}_{2}\right]^{+} 295.1685} \\
\text { Typical fragment } 283.1694 \\
\text { Typical fragment } 255.1414 \\
{[2 \mathrm{M}+\mathrm{H}]^{+} 725.4254}\end{array}$ & Diterpene & $\begin{array}{l}\text { 3,19-Dihydroxy-15-methoxy-ent- } \\
\text { labda-8(17),11,13-trien-16,15-olide }\end{array}$ \\
\hline 14 & 8.80 & $\begin{array}{l}{[\mathrm{M}+\mathrm{H}]^{+} 315.0829} \\
\text { Calculated }[\mathrm{M}+\mathrm{H}]^{+} 315.0869 \\
{[\mathrm{M}+\mathrm{H}-\mathrm{CO}]^{+} 287.1985} \\
{\left[\mathrm{M}+\mathrm{H}-\mathrm{CH}_{3}\right]^{+} 300.0635} \\
\text { Typical fragment } 271.0628 \\
\text { Typical fragment } 197.0524\end{array}$ & Flavone & Dihydroxydimethoxyflavone \\
\hline 15 & 8.98 & $\begin{array}{l}{[\mathrm{M}+\mathrm{H}]^{+} 697.4302} \\
{[\mathrm{M}+\mathrm{Na}]^{+} 719.4150} \\
{\left[\mathrm{M}+\mathrm{H}-3 \mathrm{H}_{2} \mathrm{O}-\mathrm{CH}_{2}\right]^{+} 629.3845} \\
{\left[\mathrm{M}+\mathrm{H}-4 \mathrm{H}_{2} \mathrm{O}-\mathrm{CH}_{2}\right]^{+} 611.3734} \\
{\left[\mathrm{M}+\mathrm{H}-4 \mathrm{H}_{2} \mathrm{O}-\mathrm{CH}_{2}-\mathrm{C}\right]^{+} 599.3704} \\
\text { Typical fragment } 297.1829 \\
\text { Typical fragment 255.1491 }\end{array}$ & Diterpene & Unknown \\
\hline
\end{tabular}

Compounds $\mathbf{2}$ and $\mathbf{3}$ have similar fragmentation pathways to produce the diagnostic aglycone fragment in positive ion mode, suggesting these compounds are O-glycosyl flavonoids. In the positive MS/MS spectra, the fragment ions with the highest abundance at $m / z 271.0568$ and 301.0673 (Table 1) suggest that their aglycone may be luteolin, 5,8,4'-trihydroxy-7-methoxyflavone, on the basis of the structures of O-glycosyl flavonoids that have been reported before from A. paniculata [6]. The structure of the sugar residue could be determined by calculating the difference between the molecular mass and the aglycone mass.

\subsection{Methodological Validation of the Quantitative Analysis}

LC-TOF instruments have been successfully applied to quantify some active molecules in many fields. Ions chromatograms can be extracted using a narrow mass window. This increases the possibility that the chromatographic peaks are free from background or co-elutes interference. The three components were analyzed by MS in ESI positive ion mode. It can be seen from Figure 3A that all targeted compounds andrographolide (6), neoandrographolide (8) and dehydroandrographolide (11) were baseline separated within $10 \mathrm{~min}$ in standard and samples, which represented an approximate five-fold reduction in the analysis time in comparison to published HPLC methods [34,35].

Quantitation was carried out working in the $\mathrm{V}$ mode using the narrow widow extracted ion chromatograms (nwXICs) of each compound (extracted using $20 \mathrm{mDa}$ window, Figure 3B,C). In ESI 
positive ion of $\mathrm{V}$ mode with a sample cone at $40 \mathrm{~V}$, [M+H-3 $\left.\mathrm{H}_{2} \mathrm{O}\right]^{+},[\mathrm{M}+\mathrm{H}-\mathrm{Glc}]^{+}$and $\left[\mathrm{M}+\mathrm{H}-2 \mathrm{H}_{2} \mathrm{O}\right]^{+}$ (297.1873, 319.2267 and 297.1873) for compounds 6, 8 and $\mathbf{1 1}$ were considered better stability and higher abundance. Therefore, the narrow widow extracted ions 297.1873 and 319.2267 were chosen for quantitation for compounds 6, 8 and 11 (Figure 3B,C). The analytes were identified by comparing their retention times and accurate $\mathrm{m} / \mathrm{z}$ data with standard solutions containing the corresponding compounds.

It is well-known that the occurrence of matrix effects in LC-MS has an important impact on the quantitation of the constituents in complex plant samples. Matrix effects can influence the response when compared to standards in neat solvents. In this work, the A. paniculata samples and samples added with different concentrations of standard solutions were analyzed using LC-TOF/MS, and the result was compared to standards in solvent (methanol without matrix). Relative recoveries were used to determine the matrix effects: relative recoveries $=$ (sample contents with adding-original contents)/contents of standard solutions for adding. The relative recoveries for all three compounds ranged between $93.7 \%$ and $112 \%$, thus showing minimal matrix suppression or enhancement of this method.

Table 2 provides the validation parameters including calibration curves, linearity ranges, LODs, and LOQs. As can be seen, linearity of analytical response is excellent with correlation coefficients higher than 0.9995 offering a linear dynamic range of about two orders of magnitude, which is enough to promise successful quantitative applications in routine analysis and quality control of $A$. paniculata. LODs of three compounds varied from $0.02 \mu \mathrm{g} / \mathrm{mL}$ to $0.06 \mu \mathrm{g} / \mathrm{mL}$, and LOQs ranged from $0.06 \mu \mathrm{g} / \mathrm{mL}$ to $0.2 \mu \mathrm{g} / \mathrm{mL}$.

Table 2. Calibration parameters of UPLC-MS analysis for the three compounds.

\begin{tabular}{cccccc}
\hline No. & Regression equation & Linear range $(\boldsymbol{\mu g} / \mathbf{m L})$ & $\boldsymbol{R}^{\mathbf{2}}$ & LODs $(\boldsymbol{\mu g} / \mathbf{m L})$ & LOQs $(\boldsymbol{\mu g} / \mathbf{m L})$ \\
\hline $\mathbf{6}$ & $\mathrm{y}=22.35 \mathrm{x}-9.56$ & $0.2-100$ & 0.9996 & 0.06 & 0.2 \\
$\mathbf{8}$ & $\mathrm{y}=46.00 \mathrm{x}-18.88$ & $0.2-100$ & 0.9995 & 0.02 & 0.06 \\
$\mathbf{1 1}$ & $\mathrm{y}=13.25 \mathrm{x}+5.813$ & $1.0-100$ & 0.9998 & 0.06 & 0.2 \\
\hline
\end{tabular}

The intra-day and inter-day precisions were investigated by determining the three constituents in a A. paniculata sample six times per day and on three consecutive days. The intra-day and inter-day precisions of the determination of the three constituents were less than $3.3 \%$ and $4.2 \%$, respectively.

The relative recovery experiment results showed acceptable losses in pretreatment procedure of A. paniculata and its preparations in three different levels with recoveries ranged from $96.7 \%$ to $104.5 \%$ with the relative standard deviations (RSDs) less than $2.72 \%$.

The developed fast LC-TOF/MS method was then applied to analysis of three analytes in 10 samples, i.e., four raw materials of A. paniculata, three Andrographis tables and three Andrographis extracts. The analytical contents were summarized in Table 3. The results demonstrate a successful application of this fast RRLC-ESI-TOF/MS assay for the quantification of the major active compounds in different $A$. paniculata samples and preparations. 
Table 3. Description of the test samples.

\begin{tabular}{cccccc}
\hline No. & Source & Geographical regions & Comp. $^{\text {a }}$ & Comp. $^{\text {b }}$ & Comp. 11 $^{\mathbf{c}}$ \\
\hline 1 & A. paniculata & Unknown & 0.23 & 0.27 & 0.07 \\
2 & A. paniculata & Guangxi & 0.65 & 0.73 & 0.80 \\
3 & A. paniculata & Jiangxi & 0.24 & 0.04 & 0.09 \\
4 & A. paniculata & Unknown & 1.08 & 0.16 & 0.25 \\
5 & Andrographis Extract & Sichuan & 6.73 & 11.95 & 10.75 \\
6 & Andrographis Extract & Sichuan & 3.56 & 9.28 & 16.54 \\
7 & Andrographis Extract & Sichuan & 7.24 & 9.68 & 17.45 \\
8 & Andrographis Tablet & Guangxi Fanglue & 1.35 & 0.83 & 0.67 \\
9 & Andrographis Tablet & Heilongjiang Wusulijiang & 0.33 & 0.42 & 0.52 \\
10 & Andrographis Tablet & Guangdong Boluoxianfeng & 1.61 & 0.63 & 0.69 \\
\hline${ }^{a}$ Comp. 6, andrographolide; ${ }^{b}$ Comp. 8, neoandrographolide; ${ }^{c}$ Comp. 11, dehydroandrographolide. \\
A. paniculata and Andrographis extracts are expressed as g/g $\times 100 \%$, while Andrographis tablet are \\
expressed as g/tablet $\times 100 \%$.
\end{tabular}

\section{Experimental}

\subsection{Chemicals and Reagents}

Chromatography grade methanol was purchased from Merck (Darmstadt, Germany). Deionized water was purified by Milli-Q system (Millipore, Bedford, MA, USA). A. paniculata and its commercial samples can be seen in Table 3. Standards of andrographolide, dehydroandrographolide and neoandrographolide were all ordered from the Chinese National Institute of Control of Pharmaceutical and Biological Products (Beijing, China). Their structures can be seen in Figure 1. All other reagents were of analytical grade.

\subsection{Analytical Sample Preparation}

The dried powders of $A$. paniculata $(0.2 \mathrm{~g}, 40 \mathrm{mesh})$ were accurately weighed and extracted for 30 min under $50 \mathrm{~Hz}$ ultrasound with $10 \mathrm{~mL}$ of $70 \%$ ethanol solution. Then the resultant mixture was adjusted to the original weight and the supernatant were filtered through a $0.22 \mu \mathrm{m}$ membrane before RRLC injection. Meanwhile, the sugar-coating of 10 Andrographis tablets was removed and they were porphyrized in a porcelain mortar. The Andrographis tablet powders were extracted under ultrasound with $10 \mathrm{~mL}$ of $70 \%$ ethanol solution for $30 \mathrm{~min}$. Then the resultant mixture was adjusted to the original weight and the supernatant were filtered through $0.22 \mu \mathrm{m}$ membrane before RRLC injection. The dried powders of Andrographis extract (1.0 g) were accurately weighed and dissolved in a $25 \mathrm{~mL}$ volumetric flask with of $70 \%$ ethanol. The ethanol solution was filtered through a $0.22 \mu \mathrm{m}$ filter membrane for RRLC injection.

\subsection{RRLC-TOF Apparatus and Conditions}

The RRLC-MS analysis was performed on a LC2010 HPLC system (Shimadzu, Kyoto, Japan) coupled with a Waters Premier MS equipped with electrospray ionization. For the reversed-phase RRLC analysis, an ACE Excel 3 Super C18 column $(100 \mathrm{~mm} \times 2.1 \mathrm{~mm}$ i.d., $3.0 \mu \mathrm{m})$ was used. The 
column temperature and sample temperature were maintained at $35^{\circ} \mathrm{C}$ and $4{ }^{\circ} \mathrm{C}$, respectively; the flow rate of the mobile phase was $0.20 \mathrm{~mL} / \mathrm{min}$; the injection volume was fixed at $2.0 \mu \mathrm{L}$. Mobile phase A consisted of $0.1 \%$ formic acid in acetonitrile, while mobile phase $\mathrm{B}$ consisted of $0.1 \%$ formic acid in water. The column was eluted with a linear gradient of 30\%-40\% A over initial to $2.0 \mathrm{~min}, 40 \%-75 \% \mathrm{~A}$ over 2.0-8.0 $\mathrm{min}, 75 \%-100 \%$ A over $8.0-9.0 \mathrm{~min}, 100 \%-30 \%$ A over $9.0-9.5 \mathrm{~min}, 30 \%$ A over $9.5-15.0 \mathrm{~min}$.

The mass spectrometric full-scan data were acquired in the positive ion by $\mathrm{V}$ mode from 100 to $1,000 \mathrm{Da}$ with a $0.1 \mathrm{~s}$ scan time. Other conditions were as follows: capillary voltage of $4.0 \mathrm{kV}$, desolvation temperature of $350{ }^{\circ} \mathrm{C}$, sample cone voltage of $40 \mathrm{~V}$, extraction cone voltage of $3.0 \mathrm{~V}$, source temperature of $100{ }^{\circ} \mathrm{C}$, cone gas flow of $50 \mathrm{~L} / \mathrm{h}$ and desolvation gas flow of $400 \mathrm{~L} / \mathrm{h}$ for negative ion mode. Data were centroided and mass was corrected during acquisition using an external reference (Lock-Spray ${ }^{\mathrm{TM}}$ ) consisting of a $0.2 \mathrm{ug} / \mathrm{mL}$ solution of leucine enkephalin infused at a flow rate of $1.0 \mu \mathrm{L} / \mathrm{min}$ via a lockspray interface, generating a reference ion for positive ion mode $\left([\mathrm{M}+\mathrm{H}]^{+}=556.2771\right)$ to ensure accuracy during the MS analysis.

\subsection{Standard Preparation and Calibration Curves}

An ethanol stock solution containing all three reference standards was prepared by dissolving the reference standards in ethanol to a final concentration of $500 \mu \mathrm{g} / \mathrm{mL}$ for each reference standard, then diluted the mixture stock solution to appropriate concentration to establish calibration curves. Each calibration curve concentration was performed in triplicate. All calibration curves were constructed from peak areas of reference standards versus their concentrations. The lowest concentration of working solution was diluted with ethanol to yield a series of appropriate concentrations, and the LOD and LOQ under the chromatographic conditions were separately determined at an S/N of 3 and 10, respectively. The results were listed in Table 2.

\section{Conclusions}

The chemical fingerprint profile of $A$. paniculata was systematically investigated by the RRLC-TOF/MS technique. A total of fifteen compounds were identified or tentatively characterized in A. paniculata. Furthermore, quantification of three bioactive components was carried out using RRLC-TOF, which could provide useful information for quality control of $A$. paniculata. This study would facilitate the quality evaluation of $A$. paniculata for safe and efficacious use and be a powerful reference for the identification of similar compounds presented here by MS spectra.

\section{Acknowledgments}

Our work was supported by the Heilongjiang Province Natural Science Foundation (No. D0350).

\section{Conflicts of Interest}

The authors declare no conflict of interest. 


\section{References}

1. Chao, W.W.; Kuo, Y.H.; Lin, B.F. Anti-inflammatory activity of new compounds from

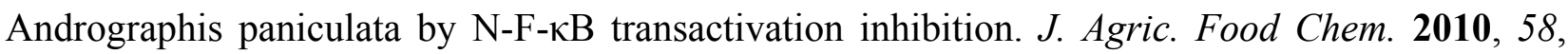
2505-2512.

2. State Pharmacopoeia Committee. Pharmacopoeia of People's Republic of China (2010 version); People's Medical Publishing House: Beijing, China, 2010.

3. Melchior, J.; Spasov, A.; Ostrovskij, O.; Bulanov, A.; Wikman, G. Double-blind, placebo-controlled pilot and Phase III study of activity of standardized Andrographis paniculata Herba Nees extract fixed combination (Kan jang) in the treatment of uncomplicated upper-respiratory tract infection. Phytomedicine 2000, 7, 341-350.

4. Gabrielian, E.; Shukarian, A.; Goukasova, G.; Chandanian, G.; Panossian, A.; Wikman, G.; Wagner, H. A double blind, placebo-controlled study of Andrographis paniculata fixed combination Kan Jang in the treatment of acute upper respiratory tract infections including sinusitis. Phytomedicine 2002, 9, 589-597.

5. Wiart, C.; Kumar, K.; Yusof, M.; Hamimah, H.; Fauzi, Z.; Sulaiman, M. Antiviral properties of ent-labdene diterpenes of Andrographis paniculata nees, inhibitors of herpes simplex virus type 1. Phytother. Res. 2005, 19, 1069-1070.

6. Koteswara Rao, Y.; Vimalamma, G.; Venkata Rao, C.; Tzeng, Y.-M. Flavonoids and andrographolides from Andrographis paniculata. Phytochemistry 2004, 65, 2317-2321.

7. Smith, P.L.; Maloney, K.N.; Pothen, R.G.; Clardy, J.; Clapham, D.E. Bisandrographolide from Andrographis paniculata activates TRPV4 channels. J. Biol. Chem. 2006, 281, 29897-29904.

8. Chen, L.; Zhu, H.; Wang, R.; Zhou, K.; Jing, Y.; Qiu, F. Ent-labdane diterpenoid lactone stereoisomers from Andrographis paniculata. J. Nat. Prod. 2008, 71, 852-855.

9. Chen, L.X.; Qiu, F.; Wei, H.; Qu, G.X.; Yao, X.S. Nine new ent-labdane diterpenoids from the aerial parts of Andrographis paniculata. Helv. Chim. Acta 2006, 89, 2654-2664.

10. Chao, C.Y.; Lii, C.K.; Hsu, Y.T.; Lu, C.Y.; Liu, K.L.; Li, C.C.; Chen, H.W. Induction of heme oxygenase-1 and inhibition of TPA-induced matrix metalloproteinase-9 expression by andrographolide in MCF-7 human breast cancer cells. Carcinogenesis 2013, 34, 1843-1851.

11. Chen, W.; Feng, L.; Nie, H.; Zheng, X. Andrographolide induces autophagic cell death in human liver cancer cells through cyclophilin D-mediated mitochondrial permeability transition pore. Carcinogenesis 2012, 33, 2190-2198.

12. Guan, S.P.; Tee, W.; Ng, D.S.; Chan, T.K.; Peh, H.Y.; Ho, W.E.; Cheng, C.; Mak, J.C.; Wong, W.S. Andrographolide protects against cigarette smoke-induced oxidative lung injury via augmentation of Nrf2 activity. Br. J. Pharmacol. 2013, 168, 1707-1718.

13. Jayakumar, T.; Hsieh, C.Y.; Lee, J.J.; Sheu, J.R. Experimental and clinical pharmacology of Andrographis paniculata and Its major bioactive phytoconstituent andrographolide. Evid. Based Complement. Alternat. Med. 2013, 2013, 846740.

14. Shen, T.; Yang, W.S.; Yi, Y.S.; Sung, G.H.; Rhee, M.H.; Poo, H.; Kim, M.Y.; Kim, K.W.; Kim, J.H.; Cho, J.Y. AP-1/IRF-3 targeted anti-Inflammatory activity of andrographolide isolated from Andrographis paniculata. Evid. Based Complement. Alternat. Med. 2013, 2013, 210736. 
15. Uttekar, M.M.; Das, T.; Pawar, R.S.; Bhandari, B.; Menon, V.; Nutan; Gupta, S.K.; Bhat, S.V. Anti-HIV activity of semisynthetic derivatives of andrographolide and computational study of HIV-1 gp120 protein binding. Eur. J. Med. Chem. 2012, 56, 368-374.

16. Zhu, T.; Wang, D.X.; Zhang, W.; Liao, X.Q.; Guan, X.; Bo, H.; Sun, J.Y.; Huang, N.W.; He, J.; Zhang, Y.K.; Tong, J.; Li, C.Y. Andrographolide protects against LPS-induced acute lung injury by inactivation of NF-kappaB. PLoS One 2013, 8, e56407.

17. Chen, L.; Jin, H.; Ding, L.; Zhang, H.; Wang, X.; Wang, Z.; Li, J.; Qu, C.; Wang, Y.; Zhang, H. On-line coupling of dynamic microwave-assisted extraction with high-performance liquid chromatography for determination of andrographolide and dehydroandrographolide in Andrographis paniculata Nees. J. Chromatogr. A 2007, 1140, 71-77.

18. Cheung, H.Y.; Cheung, C.S.; Kong, C.K. Determination of bioactive diterpenoids from Andrographis paniculata by micellar electrokinetic chromatography. J. Chromatogr. A 2001, 930, 171-176.

19. Pholphana, N.; Rangkadilok, N.; Thongnest, S.; Ruchirawat, S.; Ruchirawat, M.; Satayavivad, J. Determination and variation of three active diterpenoids in Andrographis paniculata (Burm.f.) Nees. Phytochem. Anal. 2004, 15, 365-371.

20. Qizhen, D.; Jerz, G.; Winterhalter, P. Separation of andrographolide and neoandrographolide from the leaves of Andrographis paniculata using high-speed counter-current chromatography. J. Chromatogr. A 2003, 984, 147-151.

21. Srivastava, A.; Misra, H.; Verma, R.K.; Gupta, M.M. Chemical fingerprinting of Andrographis paniculata using HPLC, HPTLC and densitometry. Phytochem. Anal. 2004, 15, 280-285.

22. Xu, T.; Pan, J.; Zhao, L. Simultaneous determination of four andrographolides in Andrographis paniculata Nees by silver ion reversed-phase high-performance liquid chromatography. J. Chromatogr. Sci. 2008, 46, 747-750.

23. Xu, X.Q.; Hu, G.L.; Shen, J.C.; Li, Q.; Wang, X.R. Determination of andrographolide and dehydroandrographolide in Andrographis paniculata nees materials and related patent medicines by reversed-phase high performance liquid chromatography. Se Pu 2002, 20, 446-448.

24. Zhao, J.; Yang, G.; Liu, H.; Wang, D.; Song, X.; Chen, Y. Determination of andrographolide, deoxyandrographolide and neoandrographolide in the Chinese herb Andrographis paniculata by micellar electrokinetic capillary chromatography. Phytochem. Anal. 2002, 13, 222-227.

25. Yang, M.; Wang, J.; Kong, L. Quantitative analysis of four major diterpenoids in Andrographis paniculata by ${ }^{1} \mathrm{H}$ NMR and its application for quality control of commercial preparations. J. Pharm. Biomed. Anal. 2012, 70, 87-93.

26. Valachovic, P.; Pechova, A.; Mason, T. Towards the industrial production of medicinal tincture by ultrasound assisted extraction. Ultrason. Sonochem. 2001, 8, 111-117.

27. Xia, E.Q.; Yu, Y.Y.; Xu, X.R.; Deng, G.F.; Guo, Y.J.; Li, H.B. Ultrasound-assisted extraction of oleanolic acid and ursolic acid from Ligustrum lucidum Ait. Ultrason. Sonochem. 2012, 19, 772-776.

28. Ding, L.; Luo, X.B.; Tang, F.; Yuan, J.B.; Guo, M.; Yao, S.Z. Quality control of medicinal herbs Fructus gardeniae, common andrographis herb and their preparations for their active constituents by high-performance liquid chromatography-photodiode array detection-electrospray mass spectrometry. Talanta 2008, 74, 1344-1349. 
29. Yang, T.; Xu, C.; Wang, Z.T.; Wang, C.H. Comparative pharmacokinetic studies of andrographolide and its metabolite of 14-deoxy-12-hydroxy-andrographolide in rat by ultra-performance liquid chromatography-mass spectrometry. Biomed. Chromatogr. 2013, 27, 931-937.

30. Lim, J.C.W.; Chan, T.K.; Ng, D.S.; Sagineedu, S.R.; Stanslas, J.; Wong, W. Andrographolide and its analogues: Versatile bioactive molecules for combating inflammation and cancer. Clin. Exp. Pharmacol. Physiol. 2012, 39, 300-310.

31. Matsuda, T.; Kuroyanagi, M.; Sugiyama, S.; Umehara, K.; Ueno, A.; Nishi, K. Cell differentiation-inducing diterpenes from Andrographis paniculata Nees. Chem. Pharm. Bull. 1994, 42, 1216.

32. Wu, W.; Yan, C.; Li, L.; Liu, Z.; Liu, S. Studies on the flavones using liquid chromatography-electrospray ionization tandem mass spectrometry. J. Chromatogr. A 2004, 1047, 213-220.

33. Fabre, N.; Rustan, I.; de Hoffmann, E.; Quetin-Leclercq, J. Determination of flavone, flavonol, and flavanone aglycones by negative ion liquid chromatography electrospray ion trap mass spectrometry. J. Am. Soc. Mass Spectrom. 2001, 12, 707-715.

34. Dong, H.J.; Zhang, Z.J.; Yu, J.; Liu, Y.; Xu, F.G. Chemical fingerprinting of Andrographis paniculata (Burm. f.) Nees by HPLC and hierarchical clustering analysis. J. Chromatogr. Sci. 2009, 47, 931-935.

35. Lin, Q.; Kuang, Y.H.; Huang, L.; Yao, X.H.; Wang, Z.M.; Wang, D.Q.; Li, C.Y. Determination of lactones in andrographis herba and its preparation by quantitative analysis of multi-components by single-marker. Chinese Herb. Med. 2012, 43, 2406-2411.

Sample Availability: Samples of the compounds 6, 8 and $\mathbf{1 1}$ are available from the authors.

(C) 2013 by the authors; licensee MDPI, Basel, Switzerland. This article is an open access article distributed under the terms and conditions of the Creative Commons Attribution license (http://creativecommons.org/licenses/by/3.0/). 